\title{
Tongue pressure and endurance in patients with Class II and Class III malocclusion
}

\author{
Laís de Fátima Menezes ${ }^{(1)}$ \\ Alípio Miguel da Rocha Neto(1) \\ Clarissa Evelyn Bandeira Paulino ${ }^{(1)}$ \\ José Rodrigues Laureano Filho(1) \\ Luciana Moraes Studart-Pereira(1)
}

(1) Universidade Federal de Pernambuco, Recife, Pernambuco, Brasil.

Conflict of interests: Nonexistent

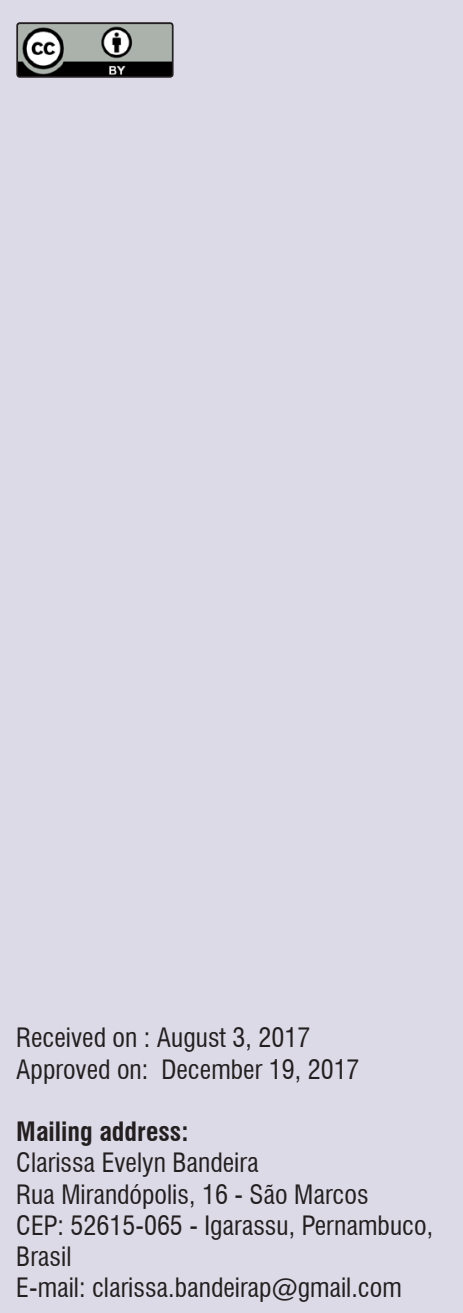

\section{ABSTRACT}

Objective: to evaluate pressure and endurance exerted by the tongue and their association with malocclusion, gender and age in orthognathic surgery candidates.

Method:a cross-sectional, descriptive observational study, performed with 34 subjects, i.e., 18 women and 16 men, in the average age 28.7 years, sorted by Angle's classification. Self-reported complaint of tongue mobility and stomatognathic functions was assessed and the evaluation of tongue mobility carried out. Tongue pressure and endurance were measured with the lowa Oral Performance Instrument (IOPI). The data were analyzed descriptively and, for inferential analysis, the Pearson Chi-Square test was used. A $5 \%$ significance level was considered.

Results: the assessed pressure and tongue endurance values of patients with malocclusion were lower than the reference ones, indicating a statistical significance in class II female patients. There was an association between inadequate pressure and tongue endurance in women with class II malocclusion. Pressure and tongue endurance in females were slightly higher than in males and a gradual decrease in averages of pressure and tongue endurance with advancing age was seen.

Conclusion: pressure and tongue endurance values in women presented with class II malocclusion were lower than the reference ones, an association between inadequate pressure and tongue endurance being found.

Keywords: Dentofacial Deformities; Malocclusion; Tongue 


\section{INTRODUCTION}

The tongue, along with the rest of the stomatognathic system structures develops key role in carrying out the vital functions of chewing, swallowing and sucking, as well as the adaptive function of speech ${ }^{1}$. Suitable pressure of the tongue is crucial so that these functions are fully performed and coupled with the pressure exerted by the external muscles of the cheeks and lips providing stability of the dental arches ${ }^{2-5}$.

The required balance due to the pressure exerted by the tongue may change in the presence of dentofacial deformities ${ }^{6}$. In the Sleiman's study with class II patients 7 , it was verified inadequate tongue posture with the high back, due to the lack of jaw space; parted lips posture with superior hypotonic and lower hypertonic. Changes in speech were also observed, dentilingual phonemes, sibilant and alveolar.

Pereira et al. ${ }^{8}$ found that patients with class III malocclusion generally exhibit myofunctional changes as: parted lips posture or sealed with pressure, hypotonic jaw elevator muscles, recessed tongue positioning in the floor of the mouth. During the function, it was observed that chewing is performed predominantly with vertical movements. It was also found, tongue thrust swallowing, and forward displacement of the tongue during speech.

The tongue force can be evaluated perceptually, widely used in speech-language therapy and through measurement instruments, which is distinguished by the ability to quantify, in a sensible way, small changes in pressure ${ }^{9}$.

Since the 1980's, researchers have sought for tools that allow the measurement of the pressure of the tongue and lips. Thenceforth, several devices have been developed for this purpose. By the year 2011, approximately thirty tools were described with the objective of quantifying the pressure exerted by the tongue and lips. Efforts are also aimed at improving these devices making them more portable and efficient ${ }^{10}$.

In this study we used the lowa Oral Performance Instrument (IOPI). This device was chosen, among many others, because it is a portable, easy to clean and use, for its high technology and data accuracy.

The finding that the tongue posture, as well as carrying out functions involving this structure tends to adapt to structural changes ${ }^{7,8}$, became interested in quantifying the pressure and endurance exerted by this body in the presence of dentofacial deformities , it is believed that the understanding of these events can serve as support for the verification of the adaptations developed by the stomatognathic system in the presence of maxillomandibular discrepancies in the definition of therapeutic possibilities as well as in identifying the limitations of operation.

Considering the above, the objective of this study was to evaluate the pressure and endurance exerted by the tongue and its association with malocclusion, sex and age of orthognathic surgery candidates.

\section{METHODS}

This was a cross-sectional, observational quantitative and descriptive research. It was approved by the Ethics and Research in Human Beings of the Federal University of Pernambuco, with the approval number: 1780737 and held in a university hospital with eligible patients for orthognathic surgery.

The study population was made of 34 volunteers, 18 women and 16 men, aged between 17 to 41 years old, with an average age of $28.7 \pm 8.29$ years. Participants were divided, according to Angle classification, in class II with 8 subjects and class III with 26 .

Eligible subjects would have to be 17 years of age or older, with class II or III malocclusion, with all permanent teeth except the third molars. Patients with neurological disorders, cognitive disorders, syndromes, with facial trauma history or head and neck cancer, or have been subjected to orthognathic surgery or speech therapy were excluded.

Clinic attendees and candidates for orthognathic surgery were invited to participate in an orientation presentation and after they were advised on the procedures / objectives of the study and signed the free and informed consent form (ICF).

Initially, patients were selected based on the occlusal relationship of the dental arches by dental students. The ratio was found according to the Angle classification in class I, II and III canine and the first molar.

Further, the volunteer responded to questions related to personal identification, recorded the presence or absence of self-reported complaint in tongue mobility, chewing, swallowing and speaking.

Then the subjects underwent myofunctional evaluation, focusing on tongue mobility. For evaluation of this performance, we used the adapted item of the AMIOFE ${ }^{11}$ tongue movements protocol. It was requested that the patient performed the following movements: protract and retract the tongue, play with 
the tongue from the right to left corners of the mouth, and click the tongue ${ }^{12}$.

The researcher recorded the movements in video with a Nikon D3300 18-55mm camera to enable further replay if needed. For this take, the patient sat with his head in normal position, and was told that he opened his mouth and perform the required movements. If the volunteer had questions as to the execution of any of them, the researcher would show the model.

Each evaluation item was scored ranging from zero to two, where zero is "normal"; one refers to the movement "reduced ability"; and two for "no skill or do not perform."

Participants who scored higher than or equal to three (the sum of all movements), meaning, did not execute any of the movements and performed another in a reduced form or carried out three with difficulty, were considered significant change in tongue mobility, and therefore did not continue in the research.

Subsequently to this evaluation, the volunteers who were able to continue in the research were advised about the measures on how the pressure and endurance of the tongue would be held. In this second stage, to evaluate these parameters, we used the lowa Oral Performance Instrument (IOPI), model 2.0.

The IOPI is an apparatus that aims to demonstrate the pressure endurance and tongue by numbers in unit kilopascal $(\mathrm{kPa})$. This instrument consists of a yield meter which allows the visualization of the force exerted on the air sensor, lingual sensor (bulbs), the connection pipe connecting the sensor to the meter, and a syringe for pressure check. It is noteworthy that, for this study, the device was calibrated as directed by the manual ${ }^{13}$, on every use in ten patients.

For tongue pressure measurement, the bulb was placed inside the patient's mouth, in the retro-incisive region, and asked him to elevate the tongue and make the maximum possible pressure against palate ${ }^{14}$. Such pressure was recorded on the device's display.

The pressure was measured three times at intervals of 30 seconds of rest. It was considered the greatest measured value of the peak pressure of the three results obtained, as provided by the IOPI ${ }^{13}$ manual.

Finally, after five minutes of rest for endurance measurement, participants were asked to follow the same guidelines for bulb placement in the oral cavity. However, for this measure should hold the pressure against the palate for as long as possible. It used $50 \%$ of its maximum pressure and the participants could monitor performance through light bar display on IOPI. The time was recorded in a chronograph ${ }^{15}$. The answers regarding the pressure and endurance were recorded in a specific form. If the participant could not run with the value of $50 \%$ of higher of the pressure gauge, was removed the average of three measurements and the endurance was conducted with half of the average value. The total collection time was around 15 minutes.

The manual of IOPI include reference data values for both of the tongue pressure in kilopascals unit $(\mathrm{kPa})$ and endurance in seconds (s) ${ }^{13}$.

The data were organized into the descriptive analysis procedure obtaining the statistical measures: average, median and standard deviation. For inferential analysis of the variables, we used the non-parametric test Pearson Chi-square. 5\% significance was adopted.

\section{RESULTS}

The results of this work were organized in tables for discussion.

First, we classified the pressure measurements and tongue endurance of Angle's class II and class III malocclusion subjects, as shown in the descriptive results in Table 1. 
Table 1. Pressure and tongue endurance expressed as average (standard deviation) and median (minimum-maximum values)

\begin{tabular}{|c|c|c|c|c|}
\hline & Tongue Pressure & Average \pm SD (kPa) & Median (kPa) & Reference Value (kPa) \\
\hline \multirow{2}{*}{ Pressure } & class II & $\begin{array}{c}27.50 \\
( \pm 11.80)\end{array}$ & $\begin{array}{l}30.00 \\
(7-42)\end{array}$ & 63.00 \\
\hline & class III & $\begin{array}{c}41.96 \\
( \pm 21.66)\end{array}$ & $\begin{array}{l}43.50 \\
(7-77)\end{array}$ & 63.00 \\
\hline \multirow{2}{*}{ Endurance } & class II & $\begin{array}{c}5.5 \\
( \pm 4.74)\end{array}$ & $\begin{array}{c}4.00 \\
(1-15)\end{array}$ & $30-35$ \\
\hline & class III & $\begin{array}{c}13.61 \\
( \pm 13.03)\end{array}$ & $\begin{array}{l}11.50 \\
(1-57)\end{array}$ & $30-35$ \\
\hline
\end{tabular}

Descriptive Analysis

Captions: $\mathrm{kPa}=$ kilopascals

It is noted that the tongue average pressure values in class II patients, are approximately $50 \%$ below the average pressure reference value IOPI described in the manual. Considerably below the average pressure is also perceived in class III population, but with slightly larger values than those found in the group previously mentioned.
Values below the average are observed in tongue endurance, and again the class II group, presented lower average figures than the class III group.

Of the three peaks of pressure recorded for each volunteer, the highest value was selected and classified as adequate and inadequate in accordance to the reference values (Table 2).

Table 2. Classification of pressure and tongue endurance adjustment, according to reference values, by Angle's classification and gender

\begin{tabular}{|c|c|c|c|c|c|}
\hline & & Adjustment & $\mathrm{n}$ & $\mathbf{N}$ & $p$-value ${ }^{1}$ \\
\hline \multirow{11}{*}{ Pressure } & \multirow{2}{*}{ class II } & Yes & 1 & \multirow{2}{*}{8} & \multirow{2}{*}{$0.03^{*}$} \\
\hline & & No & 7 & & \\
\hline & \multirow{2}{*}{ class II females } & Yes & 1 & \multirow{2}{*}{8} & \multirow{2}{*}{$0.03^{*}$} \\
\hline & & No & 7 & & \\
\hline & class II males & - & - & - & - \\
\hline & \multirow{2}{*}{ class III } & Yes & 13 & \multirow{2}{*}{26} & \multirow{2}{*}{1.00} \\
\hline & & No & 13 & & \\
\hline & \multirow{2}{*}{ class III females } & Yes & 6 & \multirow[b]{2}{*}{10} & \multirow[b]{2}{*}{0.54} \\
\hline & & No & 4 & & \\
\hline & \multirow{2}{*}{ class III males } & Yes & 7 & \multirow{2}{*}{16} & \multirow{2}{*}{0.65} \\
\hline & & No & 9 & & \\
\hline \multirow{11}{*}{ Endurance } & \multirow{2}{*}{ class II } & Yes & 2 & \multirow{2}{*}{8} & \multirow{2}{*}{0.15} \\
\hline & & No & 6 & & \\
\hline & \multirow{2}{*}{ class II females } & Yes & 2 & \multirow{2}{*}{8} & \multirow{2}{*}{0.15} \\
\hline & & No & 6 & & \\
\hline & class II males & - & & - & - \\
\hline & \multirow{2}{*}{ class III } & Yes & 15 & \multirow{2}{*}{26} & \multirow{2}{*}{0.69} \\
\hline & & No & 11 & & \\
\hline & \multirow{2}{*}{ class III females } & Yes & 8 & \multirow{2}{*}{10} & \multirow{2}{*}{$0.05^{\star}$} \\
\hline & & No & 2 & & \\
\hline & \multirow{2}{*}{ class III males } & Yes & 6 & \multirow{2}{*}{16} & \multirow{2}{*}{0.31} \\
\hline & & No & 10 & & \\
\hline
\end{tabular}

${ }^{1}$ Chi-square test - * Significant - p-value $<0.05$

Captions: $\mathrm{N}=$ total number; $\mathrm{n}=$ subgroup 
In Table 2, there was significant values on the inadequacy of the pressure exerted by the tongue of the female class II patients compared to reference values.

Regarding endurance, it can be seen in Table 2 that the class III female group presented adequate endurance, in significant values.
Table 3 shows the relationship between the inadequate pressure and endurance of the tongue with Angle's class II malocclusion in female patients. Both with statistical significance. Unable to parse the tongue pressure of class II male due to the lack of volunteers who would fit in this group.

Table 3. Association between pressure and tongue endurance according to reference values, and occlusion in female subjects

\begin{tabular}{|c|c|c|c|c|c|}
\hline & \multirow{3}{*}{ Occlusion } & \multicolumn{4}{|c|}{ Women } \\
\hline & & \multicolumn{3}{|c|}{ Adjustment } & \multirow{2}{*}{$\mathrm{p}$-value } \\
\hline & & Yes & No & Total & \\
\hline \multirow{3}{*}{ Pressure } & class II & 1 & 7 & 8 & \\
\hline & class III & 10 & 0 & 10 & \\
\hline & Total & 11 & 7 & 18 & $.000^{*}$ \\
\hline \multirow{3}{*}{ Endurance } & class II & 2 & 6 & 8 & \\
\hline & class III & 8 & 2 & 10 & \\
\hline & Total & 10 & 8 & 18 & $0.02^{*}$ \\
\hline
\end{tabular}

'Pearson's chi-square test - * Significant - p-value $<0.05$

Table 4 shows the classification of pressure and tongue endurance by gender. It is found that the average tongue pressure of women was slightly higher than the average in male without statistical significance. The same phenomenon happened with the average of tongue endurance.

Table 4. Pressure and tongue endurance by gender, expressed by the average (standard deviation) and median (minimum-maximum values)

\begin{tabular}{|c|c|c|c|c|}
\hline & & Average \pm SD $(\mathrm{kPa})$ & Median (kPa) & Reference Value (kPa) \\
\hline \multirow{3}{*}{ Pressure } & Females & 39.50 & 36.50 & \multirow[t]{2}{*}{63.00} \\
\hline & & $\begin{array}{c}( \pm 19.10) \\
38.00\end{array}$ & $\begin{array}{l}(1-10) \\
39.00\end{array}$ & \\
\hline & Males & $( \pm 21.77)$ & $(7-77)$ & 63.00 \\
\hline \multirow{2}{*}{ Endurance } & Females & $\begin{array}{c}13.25 \\
( \pm 13.65)\end{array}$ & $\begin{array}{l}11.00 \\
(1-57)\end{array}$ & $30-35$ \\
\hline & Males & $\begin{array}{c}10.12 \\
( \pm 9.87)\end{array}$ & $\begin{array}{c}7.50 \\
(1-38)\end{array}$ & $30-35$ \\
\hline
\end{tabular}

Descriptive Analysis

Captions: $\mathrm{kPa}=$ kilopascals; $\mathrm{s}=$ seconds

Table 5 shows a comparison of average pressure and tongue endurance in different age groups was performed. It is noticed that there is a gradual decrease of the average pressure and tongue endurance, with advancing age.
Table 6 shows the classification of pressure and tongue endurance in different age groups. 
Table 5. Pressure and tongue endurance expressed as average (standard deviation) and median (minimum-maximum values) in the age groups

\begin{tabular}{|c|c|c|c|c|c|}
\hline & Age & Average \pm SD $(\mathrm{kPa})$ & Median (kPa) & $\mathbf{N}$ & Reference Value (kPa) \\
\hline \multirow{3}{*}{ Pressure } & $<20$ years & $\begin{array}{c}43.00 \\
( \pm 19.73)\end{array}$ & $\begin{array}{c}52.00 \\
(11-67)\end{array}$ & 5 & 63.00 \\
\hline & 20 to 39 years & $\begin{array}{c}38.04 \\
( \pm 22.31)\end{array}$ & $\begin{array}{l}38.00 \\
(7-77)\end{array}$ & 25 & 63.00 \\
\hline & $40-45$ years & $\begin{array}{c}36.25 \\
( \pm 3.96) \\
\end{array}$ & $\begin{array}{c}36.00 \\
(31-42)\end{array}$ & 4 & 63.00 \\
\hline \multirow{3}{*}{ Endurance } & $<20$ years & $\begin{array}{c}20.60 \\
( \pm 14.23)\end{array}$ & $\begin{array}{l}15.00 \\
(4-37)\end{array}$ & 5 & $30-35$ \\
\hline & 20 to 39 years & $\begin{array}{c}10.48 \\
( \pm 11.64)\end{array}$ & $\begin{array}{l}8.00 \\
(1-57)\end{array}$ & 25 & $30-35$ \\
\hline & 40-45 years & $\begin{array}{c}8.25 \\
( \pm 5.26) \\
\end{array}$ & $\begin{array}{r}6.50 \\
(3-17) \\
\end{array}$ & 4 & $30-35$ \\
\hline
\end{tabular}

Descriptive Analysis

Captions: $\mathrm{N}=$ number; $\mathrm{KPa}=$ kilopascals; $\mathrm{s}=$ seconds

Table 6. Classification of pressure and tongue endurance in different age groups

\begin{tabular}{|c|c|c|c|c|c|}
\hline & Age & Adjustment & $\mathbf{n}$ & N & p-value ${ }^{1}$ \\
\hline \multirow{6}{*}{ Pressure } & \multirow{2}{*}{$<20$ years } & Yes & 3 & \multirow{2}{*}{5} & \multirow{2}{*}{0.65} \\
\hline & & No & 2 & & \\
\hline & \multirow{2}{*}{20 to 39 years } & Yes & 11 & \multirow{2}{*}{25} & \multirow{2}{*}{0.54} \\
\hline & & No & 14 & & \\
\hline & \multirow{2}{*}{ 40-45 years } & Yes & 0 & \multirow{2}{*}{4} & \multirow{2}{*}{ - } \\
\hline & & No & 4 & & \\
\hline \multirow{6}{*}{ Endurance } & \multirow{2}{*}{$<20$ years } & Yes & 3 & \multirow{2}{*}{5} & \multirow{2}{*}{0.65} \\
\hline & & No & 2 & & \\
\hline & \multirow{2}{*}{20 to 39 years } & Yes & 12 & \multirow{2}{*}{25} & \multirow{2}{*}{0.84} \\
\hline & & No & 13 & & \\
\hline & \multirow{2}{*}{$40-45$ years } & Yes & 1 & \multirow{2}{*}{4} & \multirow{2}{*}{0.31} \\
\hline & & No & 3 & & \\
\hline
\end{tabular}

${ }^{1}$ Chi-square test - * Significant - p-value $<0.05$

Captions: $\mathrm{N}=$ total number; $\mathrm{n}=$ subgroup

It was observed that in the group of patients younger than 20 years old, just over half of the volunteers had proper tongue pressure. In the group aged 20 to 39 years, most of the volunteers had inadequacy of this parameter. Finally, the group of volunteers between
40 and 45 years, all volunteers had inadequate tongue pressure. However, as can be noted in Table 7, an association between tongue pressure and increasing age cannot be established. The same is observed as regarding endurance. 
Table 7. Association between the pressure and tongue endurance and age groups

\begin{tabular}{|c|c|c|c|c|c|}
\hline & \multirow{2}{*}{ Age } & \multicolumn{3}{|c|}{ Adequacy } & \multirow{2}{*}{$p$-value ${ }^{1}$} \\
\hline & & Yes & No & Total & \\
\hline \multirow{4}{*}{ Pressure } & $<20$ years & 3 & 2 & 5 & \\
\hline & 20 to 39 years & 11 & 14 & 25 & \\
\hline & $40-45$ years & 0 & 4 & 4 & \\
\hline & Total & 14 & 20 & 34 & 0.16 \\
\hline \multirow{4}{*}{ Endurance } & $<20$ years & 3 & 2 & 5 & \\
\hline & 20 to 39 years & 12 & 13 & 25 & \\
\hline & $40-45$ years & 1 & 3 & 4 & \\
\hline & Total & 16 & 18 & 34 & 0.56 \\
\hline
\end{tabular}

${ }^{1}$ Pearson's chi-square test - * Significant - p-value $<0.05$

\section{DISCUSSION}

In general, patients with dentofacial deformities of this study showed low values of pressure and tongue endurance (Table 1).

Similar values, also below average, were found in the study of Nascimento ${ }^{16}$, which aimed to assess the tongue's myofunctional state and the suprahyoid muscles of patients with class II and class III dentofacial deformities. In the assessment of the tongue pressure over the IOPI bulb, the study found an average of $40,53 \mathrm{kpa}$ in class II malocclusion patients, and an average $40,72 \mathrm{kpa}$ in class III malocclusion patients.

The averages of the present research, were lower than those found in Rosa's ${ }^{17}$ work, whose average values of tongue pressure in patients with temporomandibular disorders (TMD) were $56.33 \mathrm{kPa}$ and 58.20 $\mathrm{kPa}$ in the control group.

This decrease in tongue pressure can be explained by changes in bone structure of the jaw and / or mandible ${ }^{18}$, characteristic in patients with DFD, which generate adjustments in the myofunctional stomatognathic system, which may cause lingual hypotonia. The tongue position in class II malocclusion, is retro positioned and high back, as class III, the tongue position is recessed into the floor of the mouth, with a broader base and flatter positioning ${ }^{19}$.

In Table 1, tongue endurance is observed in the studied groups. It can be seen that the averages are below that proposed in the IOPI manual.

In the study of Prandini ${ }^{20}$ tongue endurance in patients with cleft lip-palate was assessed, the results were higher than the current study, especially if compared to the class II group. The author found the values averaging $18.00 \mathrm{kPa}$ in volunteers with cleft lip-palate, and $21.48 \mathrm{kPa}$ in the control group.
Both for pressure values, as for endurance it was observed that the class III malocclusion population showed higher average than the class II population, giving rise to interference of the intraoral space for such measures.

In Table 2, pressure and tongue endurance of the volunteers were classified as appropriate or inappropriate according to the IOPI manual, it was observed that there were significant to inadequate pressure in the class II female group, and statistical significant for tongue endurance in the class III female population.

In table 4 , there is a comparison of average pressure and tongue endurance in males and females, the results are different to the values presented by IOPI manual for the health USA population ${ }^{13}$. In the cited reference, tongue pressure in males is about $10 \%$ higher than female in people aged 20-39 years.

The result of this study, in relation to sex, also differs, the findings of Prandini et al. ${ }^{21}$, who found values for tongue pressure on the average male of $63,94 \mathrm{kPa}$ and $50,27 \mathrm{kpa}$ for females. Regarding tongue endurance, the data from this study also differed followed by Prandini et al. ${ }^{21}$, who found values of $24,85 \mathrm{kPa}$ for males and $17.35 \mathrm{kPa}$, for females. In this study, the average female, appeared slightly larger than the male.

Taking up note that there were more women than men in this study, this fact may have given increasing trend of tongue endurance to this group.

There are controversies regarding the difference in tongue pressure between genders. In some studies, such as Lambrechts et al. ${ }^{22}$, tongue pressure in patients with braces was observed, there were no significant differences between tongue pressure and genders.

Table 5 presents the comparison of pressure and tongue endurance within the age groups, it was observed that the results were similar to the data found 
in the study of Crow and Ship in $1996^{23}$, which surveyed healthy adults finding tongue pressure averaging 75.70 $\mathrm{kPa}$ in subjects aged between 19 and 39 years old, and the average of $75.20 \mathrm{kPa}$ in participants aged 40 to 59 years. Much higher values compared with the present investigation. However, with the same gradual decrease in the average, with increasing age.

Tongue endurance in patients younger than 20 years old of age have a higher average than the population of groups aged 20 to 39 years and the latter higher than those in the age group between 40 and 45 years. The same was found in the study of Crow and Ship, $1996{ }^{23}$, where it was verified $43.9 \mathrm{kPa}$ values in the population of 19 to 39 years, and $41.9 \mathrm{kPa}$ in the population aged 40 to 59 years. This fact was expected, taking into account that, over the years, people experience a gradual loss of muscle fibers and its function. This muscle loss, is called sarcopenia ${ }^{24}$.

The results related to age further agree with the results of Van Lierde et al. (2014) ${ }^{25}$, where the age factor was significant in assessing the oral force in subjects with cleft lip and palate. However, as noted in Tables 6 and 7, although there were quantitative differences between age groups, there was no statistically significant results nor association between pressure and tongue endurance and age groups.

The findings of this study reinforce the importance of the search for harmony between the dentofacial structures, which enables the satisfactory performance of stomatognathic functions.

\section{CONCLUSION}

The tongue pressure and endurance, obtained in patients with Angle's class II and class III, were lower than those set by the IOPI manual and other studies.

The tongue pressure and endurance in females were slightly higher than in males.

There was an association between inadequate pressure and tongue endurance with Angle's Class II malocclusion in female subjects.

The pressure and tongue endurance decrease with advancing age, but it was not possible to establish this association.

\section{ACKNOWLEDGMENTS}

Laboratory of Orofacial Motricity / Aerodynamic Evaluation of Breathing and Phono-articulation of the Department of Speech, Language and Hearing Sciences of the institution of origin.

\section{REFERENCES}

1. Marchesan IQ. Avaliando e tratando o sistema estomatognático. Tratado de Fonoaudiologia. São Paulo: Roca, 1997. p. 763-80.

2. Proffit WR, Fields HW, Sarver DM. Ortodontia contemporanea. 5. ed. Rio de Janeiro: Elservier; 2012.

3. Jung $\mathrm{MH}$, Yang WS, Nahm DS. Maximum closing force of mentolabial muscles and type of malocclusion. Angle Orthod. 2010;80(1):72-9.

4. Fröhlich K, Ingervall B, Thu" er U. Further studies of the pressure from the tongue on the teeth in young adults. Eur J Orthod. 1992;14:229-39.

5. Kucukkeles, N, Ceylanoglu C. Changes in lip, cheek, and tongue pressures after rapid maxillary expansion using a diaphragm pressure transducer. Angle Orthod. 2003;73(6):662-8.

6. Sarver DM, Johnston MW. Orthognathic surgery and aesthetics: planning treatment to achieve functional and aesthetic goals. $\mathrm{Br} \mathrm{J}$ Orthod. 1993;20(2):93-100.

7. Sleiman DAV. Atuação fonoaudiológica nas alterações miofuncionais orais em indivíduos com maloclusão classe II. J Bras Fonoaudiol 1999;1(1):76-82.

8. Pereira AC, Jorge, TM, Ribeiro Júnior PD, BerretinFelix G. Características das funções orais de indivíduos com má oclusão Classe III e diferentes tipos faciais. Rev. Dent. Press Ortodon. Ortop. Facial. 2005;10(6):111-9.

9. Youmans SR, Stierwalt JAG. Measures of Tongue Function Related to Normal Swallowing" Dysphagia. 2006;21(2):102-11.

10. Furlan RMMM, Valentim AF, Motta AR, Barroso MFS, Costa CGD, Las Casas EBD. Quantitative methods for assessing tongue force. Rev. CEFAC. 2012;14(6):1215-25.

11. Felício CM, Ferreira CL Protocol of orofacial myofunctional evaluation with scores. Int $\mathrm{J}$ Pediatr Otorhinolaryngol. 2008;72(3):367-75.

12. Magalhães Junior VH, Tavares JC, Magalhães $A A B$, Galvão HC, Ferreira MAF. Characterization of tongue pressure in the elderly. Audiol. Commun. Res. 2014;19(4):375-9.

13. IOPI Northwest. lowa oral performance instrument: user's manual. Carnation: IOPI Northwest; 2011.

14. Clark HM, Solomon NP. Age and sex differences in orofacial strength. Dysphagia. 2012;27(1):2-9.

15. Stierwalt JAG, Youmans SR. Tongue measures in individuals with normal and impaired 
swallowing. Am J Speech Lang Pathol. 2007;16(2)148-56.

16. Nascimento KSG. Desempenho funcional da língua na deformidade dentofacial. [dissertação]. Ribeirão Preto (SP): Faculdade de Medicina de Ribeirão Preto - Universidade de São Paulo; 2015.

17. Rosa RR. Função de língua e funções orofaciais em indivíduos com disfunção temporomandibular. [tese]. Bauru (SP): Faculdade de Odontologia de Bauru - Universidade de São Paulo; 2015.

18. Silva JB, Giglio LD, Regalo SH, de Mello-Filho FV, Trawitzki LV. Effect of dentofacial deformity on maximum isometric tongue strength. $\mathrm{J}$ Oral Rehabil. 2013;40(4):247-51

19. Marchesan IQ, Bianchini EMG. A fonoaudiologia e a cirurgia ortognática. In: Araujo A (org). Cirurgia ortognática. São Paulo: Santos, 1999. p. 353-62.

20. Prandini EL. Força e mobilidade de língua na fissura labiopalatina. [dissertação]. Bauru (SP):Hospital de Reabilitação de Anomalias Craniofaciais Universidade de São Paulo; 2015.

21. Prandini EL, Totta T, Bueno MRS, Rosa RR, Giglio LD, Trawitzki LVV et al. Analysis of tongue pressure in Brazilian young adults. CoDAS. 2015;27(5):478-82.

22. Lambrechts H, De Baets E, Fieuws S, Willems G. Lip and tongue pressure in orthodontic patients. Eur $\mathrm{J}$ Orthod. 2010;32(4):466-71.

23. Crow HC, Ship JA. Tongue strength and endurance in different aged individuals. J Gerontol A Biol Sci Med Sci. 1996;51(5):M247-M250.

24. Rosenberg IH. Sarcopenia: origins and clinical relevance. J Nutr. 1997;127(5):990S-991S.

25. Van Lierde KM, Bettens K., Luyten A, Plettinck $\mathrm{J}$, Bonte $\mathrm{K}$, Vermeersch $\mathrm{H}$ et al. Oral strength in subjects with a unilateral cleft lip and palate. Int. J. Pediatr. Otorhinolaryngol. 2014;78(8):1306-10. 